\title{
New keys for old doors: breaking the vicious circle connecting homelessness and reoffending
}

\author{
Graham Bowpitt
}

Reader in Social Policy, Nottingham Trent University, Burton Street, Nottingham NG1 4BU graham.bowpitt@ntu.ac.uk

Policy-makers concerned with preventing re-offending have long been aware of the relationship between crime and homelessness. Single homeless people are more likely to be victims of violent crime, to be drawn into criminal sub-cultures and to receive custodial sentences when they offend. Likewise, offenders are more likely to re-offend in the absence of stable accommodation, while custodial sentences frequently put accommodation at risk, creating a vicious circle. This is especially true of offenders given short-term prison sentences of 3-12 months. This concern has been given a new imperative in the UK by the passing of the Offender Rehabilitation Act 2014, and the extension of statutory rehabilitation to short-term prisoners. Policy-makers concerned with effective offender management are therefore keen to explore ways in which securing stable accommodation might reduce re-offending.

This chapter seeks to provide evidence from an evaluation of a small-scale attempt to use the procurement of stable accommodation as a key element in a package of support designed to reduce the likelihood of reoffending among a particular group of offenders with short-term sentences for prolific acquisitive crime, $90 \%$ of whom were homeless at the time they were sentenced. The evaluated project is managed by a partnership between a Category B Community Prison in the English Midlands and a voluntary sector day centre for homeless adults, to which service users frequently gravitate on release. The evaluation explores the effectiveness of the project in preparing participants for release and in preventing homelessness, re-offending and social isolation. Data were gathered from interviews with service users and key informants from housing and support services to whom referrals are made, in order to advance our understanding of what mediates the relationship between acquiring and maintaining secure accommodation and reductions in criminal activity, thereby informing wider debates around prisoner rehabilitation as a policy objective.

\section{The enduring problem: homelessness and reoffending}

Concerns about reoffending rates among ex-prisoners have long occupied the minds of policymakers in the UK. The report by the Social Exclusion Unit, Reducing Re-offending by Ex-prisoners (SEU, 2002), is still regarded as something of a benchmark in tackling re-offending, partly because it was the first recognition of ex-prisoners as a multiply excluded group rather than merely a group of ex-offenders, but also because so little has changed in the intervening 12 years. Thus the $58 \%$ reconviction rate within 2 years, rising to $61 \%$ for offenders on sentences of less than 12 months, which the SEU found in 2002, was similarly recorded by the Ministry of Justice in 2011 (MoJ, 2013a).

Moreover, the SEU report showed a high degree of correlation between imprisonment and homelessness. Nearly $5 \%$ of prisoners were sleeping rough at the time of their confinement, and $32 \%$ had no secure accommodation. The longitudinal cohort study of short-term prisoners sentenced in 2005 and 2006, Surveying Prisoner Crime Reduction (MoJ, 2012a), implies things have if anything worsened in the intervening years: $9 \%$ were sleeping rough, $7 \%$ were otherwise homeless, and a further $34 \%$ would be classed as vulnerably housed, having no security in the accommodation 
they occupied. The survey reported a $79 \%$ reconviction rate for the homeless, compared with $47 \%$ for the accommodated. The SEU further reported that stable accommodation can reduce reconviction rates by $20 \%$. At the time, a third of prisoners lost their housing directly as a result of imprisonment, and a third reported having nowhere to stay on release, amounting to around 30,000 people a year. Moreover, less than one in five had help with securing housing prior to release.

Prisoners lose accommodation on sentence, in the end, because terminating a tenancy is often the last thing on their mind when they have just been sent to prison. As we have seen (MoJ, 2012a), 16\% are homeless anyway, and the informal arrangements on which the $34 \%$ vulnerably housed depended would in all probability end at sentence. A further $34 \%$ have their own tenancies, but are mostly unemployed and dependent on Housing Benefit. Claims can continue for a maximum of 13 weeks in the tenant's absence, but a prisoner may still be liable for rent thereafter if a notice period has to be served, or he simply fails to let the landlord know of his new situation. At discharge, prisoners are therefore likely to be both homeless and in debt, impeding future access to housing, especially if the landlord is a local authority or housing association.

Lack of accommodation on release increases the likelihood of re-offending for three reasons, enlightened by social capital theory (Halpern, 2005). Firstly, offenders needing somewhere to live will revert to existing social capital, probably their former criminal fraternity. Secondly, housing itself is a source of social capital, giving offenders an interest in staying out of prison. Thirdly, housing is a source of bridging capital, connecting them to services to address problems, and potential work opportunities.

\section{A decade of failed policy responses}

An appraisal of policy responses in England and Wales in the decade since the SEU report reveals a catalogue of ineffectiveness, but no shortage of good intentions, as the following highlights indicate. The 2002 Homelessness Act extended priority need groups to include adults vulnerable as a result of having been in detention or custody (DCLG, 2006). The 2003 Supporting People initiative, which established a fund for supported housing for people at risk of homelessness, has been highly relevant to short-term offenders with other 'vulnerabilities' e.g. mental health and substance problems. Meanwhile, in the following year, the UK Government published its response to the SEU report in its National Action Plan to reduce re-offending (Home Office, 2004). This set up the National Offender Management Service (NOMS) to take charge of resettlement, and to commit the prison service to increase the availability of housing advice in prisons, setting a target to increase the number of prisoners released with somewhere to live. As a result of this and other initiatives, the 2012 Prison Service Instruction (MoJ, 2012b) includes within its core offer a commitment to screen all new prisoners for housing need, assist them in closing down tenancies and Housing Benefit claims, provide a housing information and advice service and operate partnerships with other key stakeholders to this end.

These measures designed to improve housing access for ex-prisoners have had limited effect for two main reasons (Bowpitt et al., 2011; Homeless Link, 2011). Firstly, there are what can be termed support worker frustrations. These are felt by people often in voluntary sector homelessness organisations seeking to re-house ex-offenders who encounter exclusions arising from, for instance, landlords unwilling to accommodate people with a prison record, rent arrears or a record of antisocial behaviour, or Housing Benefit claimants more generally. This experience is then compounded by lack of integrated offender management (despite the widespread adoption of this model), lack of a co-ordinated approach to risk assessment or poor information sharing. 
However, secondly, the frustrations experienced by support workers are compounded by those encountered by discharged prisoners. Thus, advice offered in prison is not followed up with action, leaving prisoners with just their $£ 46$ discharge grant and no-one to meet them at the crucial point of discharge at the prison gate. Some complain of the narrow perspective of some services, such as probation officers facing continuous workload conflicts between their primary concern with offender management, and the more wide-ranging needs associated with prisoner rehabilitation.

Since 2010, we have seen the emergence of a new policy environment regarding prisoner rehabilitation. The 2010 Green Paper, Breaking the Cycle, (MoJ, 2010) promised a new approach to tackling re-offending. It included a commitment to tackle barriers to rehabilitation posed by inadequate access to housing. Following a more recent consultation, the UK Government set out a more far-reaching strategy in Transforming Rehabilitation: a Strategy for Reform (MoJ, 2013b), and accompanying legislation in the Offender Rehabilitation Act 2014. These measures set out more concrete commitments, including 'through the gate' support for short-term as well as long-term prisoners. Controversially, this will entail the sub-contracting of support services to Community Rehabilitation Companies, funded on a payment-by-results basis, rather than the traditional probation service.

Of considerable importance among agencies favoured to deliver rehabilitation support to discharged short-term prisoners are mentoring services, for which the Ministry of Justice has endorsed the 'justmentoring' website (Mentoring and Befriending Foundation, n.d.(a)). A quick look at its directory of mentoring services reveals 208 mentoring schemes in England and Wales that currently work with offenders, of which 123 provide housing support. According to the Mentoring and Befriending Foundation (n.d. (b)), mentoring schemes may be of two types: peer mentoring which is undertaken by fellow prisoners prior to release; and volunteer mentoring, in which volunteers are trained to sustain a relationship 'through the gate', providing friendship and support both before and after release. The aims of mentoring schemes are to target problems (e.g. lack of stable housing, social skills etc.), change behaviour (e.g. offending), expand opportunities (e.g. for work, training) and build support (e.g. trust, resilience, relationships). Their effectiveness is claimed to derive from the provision of role models, the use of social equals (if not peers), the ability to identify (preferably through first-hand experience), continuity of support (through the gate), holistic support, bridging access to services, cost-effectiveness and the building of social capital.

What do we know about the effectiveness of mentoring schemes? A review of intermediate outcomes based on 23 studies (NOMS, 2013) showed that the effect on re-offending is inconclusive, but 'through the gate' mentoring is more effective than prison only. There are also indications linking mentoring to improved outcomes in, e.g., employment, housing, addressing substance use and engagement with programmes to encourage desistance. A further study that specifically looked at peer mentoring (Fletcher and Batty, 2012) found that peer mentors may be better at engaging offenders, acting as role models, and sharing knowledge. However, the pool is small, the turnover is high, the role is ambiguous and the service needs a lot of support. Moreover, it is based on the current political assumption that all offenders need is a rehabilitative role model, forgetting the structural obstacles that earlier research found.

This brief policy review has sought to show UK prisoner rehabilitation to have reached a turning point. Decades of policy failure have left reoffending rates unchanged. The Offender Rehabilitation Act is at last attempting to put the rehabilitation of short-term prisoners on to a statutory footing by requiring them to engage with support services on release, or face the threat of recall to prison. Whether this will reduce reoffending or merely add to an ever-growing prison population will depend on the effectiveness of those support services in breaking the critical links between discharge and renewed criminality. What follows is a small-scale evaluation of a rehabilitation 
project that seeks to build on evidence that securing stable accommodation will break one of those links.

\section{The rehabilitation project and the evaluation study}

The subject of this evaluation is a prisoner rehabilitation project that combines planned post-release accommodation with the intensive personal support of a key worker and the underpinning social support of a homeless persons day centre. It is therefore designed to tackle one of the identified routes to reoffending, using a rehabilitative model with sufficiently distinct features to give it the potential for wider adoption and thus to warrant evaluation. After a brief description of the project, the methods used in the evaluation are outlined, including the characteristics of the service user and key informant samples.

The project employs an Offender Support Officer (OSO) to meet with prisoners prior to release, to prepare them for release and to support them for a period afterwards, with a particular focus on procuring stable accommodation and supporting independent living. The project is managed by a day centre in a city in the English Midlands in partnership with a local community prison, designated by the UK Ministry of Justice as one of six resettlement prisons to which prisoners are relocated prior to release. The project works with prolific repeat offenders on short-term sentences, $90 \%$ of whom are homeless at the time they are sentenced. The OSO provides a wide range of highly flexible services that can include anything that will establish service users in a stable home. However, three aspects are crucial: consistency of involvement 'through the gate', attaching priority to housing, and a personal, holistic commitment that ensures that all barriers to resettlement - whether practical or relational - are removed, so that ex-prisoners have a genuinely alternative lifestyle into which they can walk. In total, the project had provided some assistance to 270 ex-prisoners in just over two years from the beginning of 2012 to the end of February 2014.

Evidence for the effectiveness of the project is drawn from a limited, small-scale study that explored its success in sustaining re-housing, preventing re-offending and overcoming social isolation, seeking to understand the processes by which the project achieves its goals to varying degrees according to the characteristics of different service users. Data were derived from semi-structured interviews with two small samples, the first of which was an opportunity sample of six ex-prisoner service users. Interviews explored their background in terms of family, crime, work, homelessness, substance use and mental health. Respondents were invited to offer their own explanation for their current circumstances and why the current system of offender management and rehabilitation had hitherto failed in their cases. Interviews then explored their understanding of resettlement and their aspirations for the future before inviting an account of their experiences of the project, the help it had provided and the likelihood of successes being sustainable. Access to the sample was facilitated by the OSO. Service users were drawn from her caseload of service users who were typical - in terms of their characteristics, background and current circumstances - of those for whom she was currently providing intensive support. The sample of six ex-prisoners were all male and exemplified a pattern of multiple exclusion that combines offending, homelessness, family breakdown, substance misuse and mental ill-health (Bowpitt et al., 2011; Fitzpatrick et al., 2011; McDonagh, 2011). Table 1 provides introductory pen portraits, all names being fictitious. 


\begin{tabular}{|l|l|l|l|l|l|l|}
\hline \multicolumn{7}{|c|}{ Table 1: The Service User Sample } \\
\hline Age & \multicolumn{1}{|c|}{ Alan } & \multicolumn{1}{|c|}{ Brian } & \multicolumn{1}{c|}{ Clive } & \multicolumn{1}{c|}{ Hanif } & \multicolumn{1}{c|}{ Eric } & \multicolumn{1}{c|}{ Garry } \\
\hline Ethnicity & $\begin{array}{l}\text { White } \\
\text { British }\end{array}$ & $\begin{array}{l}\text { White } \\
\text { British }\end{array}$ & $\begin{array}{l}\text { White } \\
\text { British }\end{array}$ & $\begin{array}{l}\text { Middle } \\
\text { Eastern }\end{array}$ & $\begin{array}{l}\text { White } \\
\text { British }\end{array}$ & White British \\
\hline $\begin{array}{l}\text { Offending } \\
\text { background }\end{array}$ & Shoplifting & $\begin{array}{l}\text { Various } \\
\text { property- } \\
\text { related }\end{array}$ & $\begin{array}{l}\text { Domestic } \\
\text { and other } \\
\text { violence }\end{array}$ & $\begin{array}{l}\text { Contempt } \\
\text { of court }\end{array}$ & Shoplifting & Stealing \\
\hline $\begin{array}{l}\text { Current } \\
\text { accommodation }\end{array}$ & $\begin{array}{l}\text { Own } \\
\text { tenancy }\end{array}$ & $\begin{array}{l}\text { Hostel for } \\
\text { ex- } \\
\text { prisoners }\end{array}$ & $\begin{array}{l}\text { Hostel for } \\
\text { ex- } \\
\text { prisoners }\end{array}$ & $\begin{array}{l}\text { Hostel for } \\
\text { ex- } \\
\text { prisoners }\end{array}$ & $\begin{array}{l}\text { Hostel for } \\
\text { ex- } \\
\text { prisoners }\end{array}$ & $\begin{array}{l}\text { Alcohol } \\
\text { rehabilitation } \\
\text { hostel }\end{array}$ \\
\hline $\begin{array}{l}\text { Homelessness } \\
\text { background }\end{array}$ & $\begin{array}{l}\text { Slept } \\
\text { rough }\end{array}$ & $\begin{array}{l}\text { Slept } \\
\text { rough }\end{array}$ & $\begin{array}{l}\text { Slept } \\
\text { rough }\end{array}$ & $\begin{array}{l}\text { No, but at } \\
\text { risk }\end{array}$ & $\begin{array}{l}\text { Slept } \\
\text { rough }\end{array}$ & Slept rough \\
\hline $\begin{array}{l}\text { Employment } \\
\text { background }\end{array}$ & $\begin{array}{l}\text { Manual } \\
\text { unskilled }\end{array}$ & $\begin{array}{l}\text { Some } \\
\text { manual } \\
\text { skills }\end{array}$ & $\begin{array}{l}\text { Manual } \\
\text { unskilled }\end{array}$ & $\begin{array}{l}\text { Qualified } \\
\text { teacher }\end{array}$ & $\begin{array}{l}\text { Some } \\
\text { manual } \\
\text { skills }\end{array}$ & $\begin{array}{l}\text { No work for } \\
20 \text { years }\end{array}$ \\
\hline $\begin{array}{l}\text { Engagement } \\
\text { with project }\end{array}$ & $\begin{array}{l}2-3 \\
\text { months }\end{array}$ & 3 months & $\begin{array}{l}\text { Few } \\
\text { weeks }\end{array}$ & $\begin{array}{l}\text { Few } \\
\text { weeks }\end{array}$ & 3 months & $\begin{array}{l}\text { 21/2 years } \\
\text { intermittent }\end{array}$ \\
\hline
\end{tabular}

All six had been released from prison within the previous three months, and five of the six had worked with the project prior to release, mostly for just a few weeks, but intermittently for a period of $2 \frac{1}{2}$ years in Garry's case. Five were classed as prolific repeat offenders, having served a series of short-term sentences (less than 12 months) for property related crimes in four cases and offences involving violence in Clive's case. All six were accommodated at the time they were interviewed, four in the hostel for ex-prisoners, while Garry was in another hostel that focused on alcohol problems, and Alan had his own tenancy. Apart from Alan who had managed to retain his tenancy through his last brief sentence, all had been at risk of homelessness on release. Moreover, five of the six recounted a long history of homelessness, including long periods of sleeping rough, especially on release from previous sentences. All were unemployed at the time of the interviews, and with the exception of Hanif, none of the sample had experienced more than brief periods of largely unskilled employment; Garry had not worked for 20 years.

The other interview sample consisted of a purposive sample of five key informants, practitioners working for agencies that have been critical in providing move-on support. Access was once again facilitated by the OSO from amongst those with whom she collaborated in resettling service users. They included the OSO herself, a police officer working in offender management, the manager of the hostel for ex-prisoners, and support workers from two voluntary organisations providing mental health and employment support respectively. Interviews followed a similar pattern to those with service users, exploring the characteristics of the service user group that key informants typically encountered, their understanding of resettlement and what often impedes progress, and the key ingredients that make the rehabilitation project effective.

\section{Service user background and the 'vicious circle'}

The effectiveness of the project cannot be appreciated without first understanding the narratives that first drew the ex-prisoners into the vicious circle of homelessness and reoffending. In their interviews, key informants recounted a familiar story of how the effects of a damaging and traumatising childhood confront a service network ill-equipped to handle complex needs, setting people on a continually reinforcing and cumulatively destructive spiral of decline. The story begins with negative experiences of fathers who are chaotic, abusive, or die in traumatic circumstances, 
leaving an adolescent vulnerable to negative alternative male role models. The result is a disrupted education and an early introduction to drugs and a drug habit that needs to be sustained. In the absence of any regular income, acquisitive crime quickly follows. Homelessness may result from prison discharge, but more frequently it is the fall-out from inappropriate relationships formed with equally damaged young women that leave men the victims of eviction following relationship breakdown. Young men disabled by such life experiences then seek help from a welfare system almost designed to erect barriers in their faces, making reoffending the only logical survival strategy. They come out of prison with a $£ 46$ discharge grant that has to last 4-6 weeks until a benefit claim is processed. Problems associated with attending appointments for people who are homeless result in benefit sanctions, denial of medication and breach of license, making a return to prison inevitable. The struggle to secure housing encounters similar obstacles.

Much of this was confirmed by the six ex-prisoners. Alan and Brian had substantial experience of the care system, while Clive, Eric and Garry had been essentially disowned by their original families mainly because of their substance misuse. Moreover five of the six had had numerous long-term relationships that had produced children with whom they had lost contact. Five of the six had experienced serious problems with substance misuse, involving addiction to Class A drugs and alcohol. Furthermore, four had diagnosed mental health conditions for which they were receiving treatment, including Clive who described himself as a long-term paranoid schizophrenic. Substance problems were an attempt to self-medicate to mask deeper issues arising from, for instance, child abuse, relationship breakdown or mental illness. Respondents recounted a continuous cycle of substance misuse funded by petty crime which incurred short-term prison sentences from which they were invariably discharged into homelessness and further substance misuse. Homelessness frequently intervened before imprisonment when rent money was spent sustaining a drug or alcohol dependency. Encounters with the criminal justice system had done nothing to break the cycle.

More worryingly, when liberty meant little more than sleeping rough, prison acquired a positive attraction. Respondents pointed to the inevitability of homelessness and a return to criminality once they got on to the treadmill of short-term sentences and unsupported discharge. Garry described his lack of priority for re-housing, and the delays he faced when submitting a benefits claim.

When I came out, ... they can't help with rehousing and that. Just go to [local authority] the day you get out. Sometimes you go to [local authority] and they say, come back tomorrow, come back tomorrow, you're not a priority. Because you are single male with no kids and stuff. When you're trying to set up a new claim you get released with only $f 46$. Sometimes it can take 4 or 5 weeks for your new claim to be up and running. So I understand why people reoffend. I've reoffended quite a lot, coming out of jail.

To this experience, Eric added the positive appeal of prison.

To be honest with you going to jail for me was a godsend. I got fed. I got a bed. I got people to sit and listen to me talk - inmates. I mattered. Out here I don't matter. In jail I mattered. I was in a bad point. No-one wanted to know me when I was out here. When I was in jail I got people to talk to. I got warm. I'd got no concerns. I didn't matter out here. ... I could have died and nobody would have bothered with me.

\section{Establishing the present}

Findings from the evaluation are presented in the next two sections. The first explores the process of prison discharge and its immediate aftermath, seeking to identify the key ingredients that made a difference in establishing a new life away from drugs, crime and homelessness. Respondents could not over-emphasise the importance of the first ingredient, the establishment of a relationship inside prison, followed by the personal meeting at the prison gate on release. Eric described how he came across the project and its significance. 'I spoke to another inmate and he said [the project] from [day centre]. So I asked for a leaflet about services and whatever and [OSO] came to visit me in prison and she told me about all the services and all the help that can be provided for me. That was like a 
big door opened up for me. I'd never had this before.' Moreover, 'When I got out, she actually met me at the gate. If she' $d$ not been there, l'd have ended up going back to [home town] and I'd be messed up on drugs again.' This was confirmed by key informants. As the OSO explained, 'I go and see prisoners on the wing and set up a care plan for their release and when appropriate I meet them at the gate and continue to support them afterwards.' The hostel manager explained the enormous pressures on offenders with drug problems at the point of release, from which only a meeting at the gate can divert them.

The second ingredient was an attention to detail that turned the procurement of accommodation into the setting up of a home and the wherewithal to live in it. Alan was pleased that someone had kept his tenancy in order while he was in prison. For four of the others, the result of this attention to detail was a pre-arranged room in the hostel for ex-prisoners, which circumvented the standard local authority homelessness application that so often ends in failure (Dwyer et al., 2014). However, even a room in a hostel needs furnishing, and Brian described how 'she took me to [recycled furniture store], you know to get all me furniture and that. She took us there and fetched us back.' Moreover, in recognition of likely delays in benefit, several respondents were glad that the project operated from a homeless person's day centre where they could get regular meals and food hampers to obviate the need to commit further offences just in order to survive. Furthermore, knowing that failure to attend appointments had frequently triggered a downward spiral in the past, the OSO would frequently accompany service users to meetings at the Job Centre or the Probation Service, not simply to ensure they got there on time, but to act as a mediator. For Clive, taking him to places in the car reduced the chances of further paranoid episodes on public transport, for which he had been arrested in the past. As the mental health support worker realised, prioritising housing for this group entails a lot more than just fixing up a tenancy. If 'you take somebody who has been rough sleeping for 20 years and you put them in a flat, they are contained but that doesn't solve the problem'. Housing is critical to accessing a range of other services, but 'resettlement should be holistic. It's not just about housing. ... It needs to be accessible for guys and it needs to be flexible and long term.' This has important implications for debates around 'housing first' (Johnsen and Teixeira, 2010; Pleace and Quilgars, 2013).

The underpinning support of the day centre from which the project operated provided an invaluable third ingredient in the early days following release. It provided an unobtrusive means by which the OSO could maintain contact. As Alan explained, 'Even if I don't see her, she always phones me up to make sure I'm all right. Ask me, why haven't I been down [to the day centre]? Basically, checking up on me in the nicest possible way. She's like a second mum.' Moreover, securing access to the day centre provided more than just a source of free food. It offered an alternative social network where Brian felt he would be accepted and understood and not lured back into his old lifestyle. This was 'because they treat you as a human being, rather than some object, ... or some criminal. They don't try and judge you. A lot of people, a lot of them who work down there who volunteer have gone through similar backgrounds as us.'

What all this amounted to in the eyes of key informants was a fourth ingredient, a relationship of dependability, which is ironic in a society that frowns upon services that are seen to promote dependency, but there is a difference. For the mental health support worker, dependability derives from trust, which has to be earned, 'based on the fact that you've proven to them that the advice you've given them is accurate, that actually it's going to benefit them in some way'. Crucial to earning this trust is showing that the relationship established in prison is affirmed at the prison gate and will continue afterwards. For the hostel manager, dependability is about being true to your word, but it is not about generating dependency. Quite the opposite: having someone who believes in you will promote a sense of self-belief in a population disabled by repeated failure and rejection. The OSO confirmed many of the views expressed by other key informants when she summarised the 
active ingredients in her work in terms of consistency combined with a practical flexibility that involved being there for service users when they needed her and being willing to broker access to whatever it takes to make resettlement possible, using her vast knowledge of local community services.

\section{Securing the future}

Nevertheless, the key test of the project lay in its effectiveness in sustaining re-housing, preventing re-offending and overcoming social isolation. None of the sample had been charged with further offences since their most recent spell in prison. However, service users had three further aspirations which they associated with long-term resettlement: overcoming substance dependencies, finding an occupation, paid if possible, and restoring lost relationships often with children. If these were achieved, the more short-term goal of staying out of prison would follow naturally. There was a sense that these were not just aspirations in themselves; they were mutually reinforcing, and a means of ensuring an end to criminality. In this second findings section, we will see how far project and service user aspirations were realised.

How far had respondents succeeded in accessing long-term housing? With the exception of Alan who had his own tenancy, the other five respondents were all in short-term supported accommodation and recognised their need for somewhere more permanent. Initially, Brian was happy to have 'got a roof over me head, that's not a night shelter' where he could feel some sense of ownership and could say, 'this room is all mine. I've not had no possessions not ever. It does feel good knowing you've got something.' However, for Garry, resettlement entailed a much fuller community reintegration in which housing was central, and from which everything else followed. 'Resettlement is getting my own tenancy, getting somewhere to live ... managing to keep on top of the bills and shopping, just doing normal things basically, but it doesn't involve drink or drugs. Integrating. Feeling of getting back into the community.' Yet it was only for Clive that the OSO was making progress in securing permanent accommodation.

With regard to overcoming substance dependency, all six ex-prisoners were managing to abstain from drink and drugs, largely because of the regimes that operated in their current accommodation, making the choice of residence following release from prison particularly critical. Garry had 'done detox and stuff in prison', but even the abstinent environment in his hostel still required a combination of willpower and some powerful chemical supports. 'Yeah willpower. Or there's the other thing I can do, I can go on the Antabuse. If I even touch a drop of alcohol, I get violently ill.' Yet he realised that willpower and Antabuse were much more likely to succeed with something to occupy his time and attention, and here again the OSO was able to bring her fixing skills to bear. 'I' $m$ going to meet her next week for a coffee ... and see if there's anything else she can help me with. She'll be seeing me about some volunteering work and that, she knows there's a place ... a 3-day painting and decorating course, so I'm going to have a look at that.' The next stage would be paid work, using existing qualifications or gaining hew ones. 'I'd like to do some fork lift training, get my fork lift licence. I've done an industrial cleaning course; I've even been getting into that. I've got certificates for industrial cleaning.'

For some respondents, a new network of relationships, usually involving restored contact with family members, was the best hope for permanent resettlement. Garry was in no doubt that healthier relationships and activities were two of the benefits of having your own accommodation. 'I know people who don't drink, who don't do drugs. ... They don't like seeing me when I'm drunk, they don't like seeing me when I'm on drugs. I can go and visit them and we can go to the football.' Eric's real yearning was to have his children back. In the past, his criminal record and drug abuse were barriers. 'Before, when I've come out of jail ... because of my drug use (and) something like 30 shop 
thefts, they've classed me as a risk. I can't blame them for thinking that.' Now, the prospect of restored contact served as an incentive to work for the conditions that would make that happen, especially permanent accommodation and paid employment. 'I'm fighting for contact, but really my children are my inspiration now. Obviously my children need me, but I need them more.'

For the key informants, beyond the practicalities of brokering access to permanent accommodation and occupational opportunities, the project could activate other relational catalysts to sustainable resettlement. For instance, the hostel manager made good use of early successes as a learning tool in promoting a changed mind-set, restoring a sense of self-worth among people accustomed to failure. Another catalyst is the need for forbearance, of never giving up on people, recognising that effective rehabilitation needs to operate at its own pace, acknowledging the inevitability of reversals. For the hostel manager, this involves letting people return to her supported housing project to help with the practical problems of setting up home.

The possibility of the project providing a source of more lasting support raises the issue of mentoring discussed earlier. The OSO was aware that 'there's only one of me so more to be able to do this will be really helpful, for the low level support I think.' It is in this role of continuous, low level back-up for sustainable resettlement that the basing of the project at a day centre once again assumes particular significance. The employment support worker recognised in the day centre a potential source of informal mentors in providing unconditional welcome and support. 'Somebody independent who can offer you the chance to meet and not judge where you are and not be so upset by the latest story that has happened to you ... And I think that is important to have that. Definitely [the day centre] provides that for people.'

\section{Discussion}

The passing of the Offender Rehabilitation Act 2014 has generated a policy imperative to understand what works in the rehabilitation of short-term repeat offenders. This pilot evaluation of a small-scale rehabilitation project offers some contribution to this debate, especially with regard to the importance of preventing homelessness. The evaluation has shown four key elements to be effective in the short term. The first is consistency of support through the prison gate, including a personal meeting at the point of release. Not only does this serve a vital protective role, but it also testifies that promises made in prison will be kept. The second is the effective brokering of what might be called 'housing plus', that is direct accompaniment both to pre-arranged accommodation and everything else needed to make it habitable. The third is the day centre base from which the project operated, which provided both emergency access to the means of survival and access to a new social support network through the team of volunteers that operates there. The fourth is the intrinsic value of the relationship with the OSO, over and above the services thereby procured.

However, to realise its long-term goals, the rehabilitation project has to give ex-prisoners an interest in avoiding reoffending, homelessness and social isolation. It can play some role through brokering access to permanent accommodation and meaningful activities, but the pilot also showed the importance of restored family relationships and a more positive mind-set. Also of great value are the project's forbearance in allowing people to develop at their own pace, always willing to give them another chance.

This small-scale study has given some indication of what the project has been able to achieve, some of which goes beyond what is claimed for mentoring schemes. The link with a day centre that serves the needs of homeless and multiply excluded adults means that, although the OSO does not herself provide a role model, act as a social equal, or identify with the backgrounds that offenders come from, she can put service users in contact with existing volunteers who have these characteristics. 
However, of far greater value to the overall effectiveness of the service was its continuity, not simply before and after release, but actually at the prison gate at the critical point of discharge, and thereafter, enabling relationships of trust to develop. Moreover, the OSO was able to act as an effective bridge to access a range of other services, of which housing and the practical wherewithal to sustain accommodation were particularly critical. In other words, effectiveness depended on her having an expertise in a crucial area. These characteristics are not always found together in mentoring schemes.

Findings from this brief evaluation inform debates around other approaches to working with people with a history of multiple exclusion, such as personalisation, 'psychologically informed environments' (PIEs) and 'housing first'. When personalised approaches are used, for instance, with rough sleepers, service users are assigned to a single support worker with a designated budget that can be used with total flexibility for anything that would contribute to achieving agreed goals (Hough and Rice, 2010). Although the project did not assign a designated budget for each ex-offender, the flexible, holistic and personalised approach to resettlement very much mirrored the personalisation model, showing that it could work as well with other groups at risk of returning to a multiply excluded lifestyle. PIEs take this personalised approach one stage further by treating the relationship between service user and support worker as an essential ingredient in the process of change, over and above the services thereby procured (NMHDU, 2010; Keats et al., 2012). Adding further support to this approach was an unintended benefit of the project.

Although accommodation immediately on release was critical to success, its approach to housing fell well short of the 'housing first' approach to working with chronically homeless people pioneered in New York in the early 1990s and widely adopted with considerable success in other developed countries including the UK (Johnsen and Teixeira, 2010; Pleace and Quilgars, 2013). Housing First is contrasted with 'staircase' models of resettlement in accommodating homeless people directly from the street into ordinary housing, all other support services being provided separately through mobile support workers or at designated sites. Success has been achieved not only in sustaining life away from the streets, but also in addressing problems associated with mental health and substance misuse. However, there is no evidence of its use with people who are homeless on discharge from prison. Apart from Alan, all the sample were in supported accommodation with staff on site, although they had their own rooms and a high degree of self-care was expected. There is no evidence that Alan was making more progress than the other five. While there are no obvious practical limitations to independent accommodation being arranged before release, there is evidence from the present study that service users valued hostel companionship, like Eric who insisted that 'this is my family here ... I've got like a mum or a big sister here every day.'

\section{Conclusion}

The project would benefit from a more extensive evaluation with a more varied cohort who had engaged over a longer period. One of the limitations of the pilot study is that the sample had all been released from prison within the past three months, even Garry, despite his intermittent association over the past $2 \frac{1}{2}$ years. However, we can conclude that at the time of their interview, all participants had sustained their accommodation since discharge, had not been arrested for any offences, had recorded virtually no lapses into problematic substance use, and were addressing mental health problems through engagement with specialised services. To that extent, the project was a success. Critical to that success was engagement with service users prior to release, meeting them at the prison gate on release, accompanying them to pre-arranged accommodation and appointments to secure essential resources and access to key services, the flexible, holistic and personalised approach of the OSO, and the accessible, convivial and largely unconditional support of the day centre that underpinned the project. 


\section{References}

Bowpitt, G., Dwyer, P., Sundin, E. and Weinstein, M. (2011), The HOME Study: Comparing the Priorities of Multiply Excluded Homeless People and Support Agencies, Salford: University of Salford.

DCLG (Department for Communities and Local Government, 2006), The Homelessness Code of Guidance for Local Authorities, London: DCLG.

Dwyer, P., Bowpitt, G., Sundin, E. and Weinstein, M. (2014), 'Rights, responsibilities and refusals: homelessness policy and the exclusion of single homeless people with complex needs', Critical Social Policy, DOI: 10.1177/0261018314546311

Fitzpatrick, S., Johnsen, S. and White, M. (2011) 'Multiple exclusion homelessness in the UK: key patterns and intersections', Social Policy and Society, 10, 4: 501-512.

Fletcher, D.R. and Batty, E. (2012), Offender Peer Interventions: What do we know? Sheffield: Centre for Economic and Social Research, Sheffield Hallam University.

Halpern, D. (2005), Social Capital, Cambridge: Polity.

Home Office (2004), Reducing Reoffending: National Action Plan, London: Home Office.

Homeless Link (2011), Better Together: Preventing Reoffending and Homelessness, London: Homeless Link. Available at http://www.homeless.org.uk/sites/default/files/Better\%20Together\%20Final\%20Report Sep11 prm.pdf (Accessed 10/7/14)

Hough, J. and Rice, B. (2010), Providing Personalised Support to Rough Sleepers: An evaluation of the City of London pilot, York: Joseph Rowntree Foundation. Available at http://www.broadwaylondon.org/ResearchInformation/Research/Personalisationforroughsleepe rs.html (Accessed 10/7/14)

Johnsen, S. and Teixeira, L. (2010), 'Staircases, elevators and cycles of change: Housing First and other housing models for homeless people with complex support needs', Research Summary, York: The University of York.

Keats, H., Cockersell, P., Haigh, R., Johnson, R. and Maguire, N. (2012), Psychologically Informed Services for Homeless People, Southampton: University of Southampton College of Medicine.

McDonagh, T. (2011), Tackling homelessness and exclusion: understanding complex lives, Round up: reviewing the evidence, York: Joseph Rowntree Foundation.

Mentoring and Befriending Foundation (n.d. (a)), Justmentoring hub, available at http://www.justmentoring.org.uk/ (Accessed 9/12/14)

Mentoring and Befriending Foundation (n.d. (b)), What is mentoring and befriending? Available at http://www.mandbf.org/mbf-membership/what-is-mentoring-and-befriending (Accessed 9/12/14)

MoJ (Ministry of Justice, 2010), Breaking the Cycle: Effective Punishment, Sentencing and Rehabilitation of Offenders, $\mathrm{Cm}$ 7972, London: Crown Copyright. Available at http://webarchive.nationalarchives.gov.uk/20120119200607/http:/www.justice.gov.uk/consultat ions/docs/breaking-the-cycle.pdf (Accessed 10/7/14)

MoJ (2012a), Accommodation, Homelessness and Reoffending of Prisoners: Results from the Surveying Prisoner Crime Reduction (SPCR) survey. Available at https://www.gov.uk/government/uploads/system/uploads/attachment data/file/278806/homel essness-reoffending-prisoners.pdf (Accessed 10/7/14).

MoJ (2012b), Prison Service Instruction - Custody, PSI 12/2012. Available at http://www.justice.org.uk/offenders/psis/prison-service-instructions-2012 (Accessed 10/7/14)

MoJ (2013a), Proven Reoffending Statistics Quarterly Bulletin: July 2010 to June 2011, England and Wales. Available at https://www.gov.uk/government/uploads/system/uploads/attachment data/file/192631/prove n-reoffending-jul-10-jun-11.pdf (Accessed 10/7/14). 
MoJ (2013b), Transforming Rehabilitation: a Strategy for Reform, Cm 8619, London: Crown Copyright. Available at https://consult.justice.gov.uk/digital-communications/transformingrehabilitation/results/transforming-rehabilitation-response.pdf (Accessed 10/7/14)

NMHDU (National Mental Health Development Unit, 2010), Meeting the Psychological and Emotional Needs of Homeless People, London: NMHDU

NOMS (National Offender Management Service, 2013), Intermediate Outcomes of Mentoring Interventions: a Rapid Evidence Assessment. Available at http://www.mandbf.org.uk/wpcontent/uploads/2014/01/Intermediate-outcomes-of-mentoring-interventions.pdf (Accessed $10 / 7 / 14)$

Pleace, N. and Quilgars, D. (2013), Improving Health and Social Integration through Housing First: a Review, York: Centre for Housing Policy, University of York

SEU (Social Exclusion Unit, 2002), Reducing Reoffending by Ex-prisoners, London: Office of the Deputy Prime Minister. 